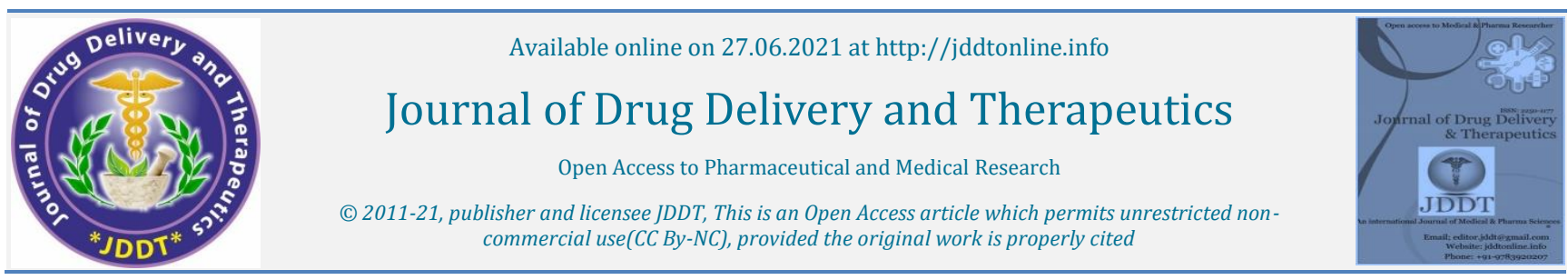

Open Access Full Text Article

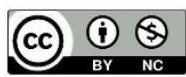

Research Article

\title{
Prevalence and Risk Factor of Chronic Rhinosinusitis and the Impact on Quality of Life in Students of the Medical Faculty Christian University of Indonesia in 2018
}

\author{
Fransiskus Harf Poluan, Lina Marlina \\ Medical Faculty, Univeristas Kristen Indonesia, Jakarta
}

$\begin{array}{ll}\text { Article Info: } & \\ & \text { Article History: } \\ & \text { Received 09 May 2021 } \\ & \text { Accepted 21 June 2021 } \\ & \text { Available online 27 June } 2021\end{array}$

Cite this article as:

Poluan FH, Marlina L, Prevalence and Risk Factor of Chronic Rhinosinusitis and the Impact on Quality of Life in Students of the Medical Faculty Christian University of Indonesia in 2018, Journal of Drug Delivery and Therapeutics. 2021; 11(3-S):154-162 DOI: http://dx.doi.org/10.22270/jddt.v11i3-S.4846

\section{*Address for Correspondence:}

Fransiskus Harf Poluan, Medical Faculty, Univeristas Kristen Indonesia, Jakarta

\section{Abstract}

Chronic Rhinosinusitis (CRS) is an inflammation of nasal mucose dan paranasal sinuses with $\geq$ two symptoms, one of which should be nasal blockage/ obstruction or nasal discharge (anterior/ posterior nasal drip) that happened for $\geq 12$ Weeks. CRS affects 5 $15 \%$ adult population in Europe and the United States of America, with a prevalence of 2$4 \%$ that doctors have diagnosed. The risk factors of CRS that quite often happened on CRS is allergic rhinitis. CRS also often happened in women. CRS also impact the patient's quality of life. This study aims to know the prevalence and risk factor of CRS and the impact on quality of life on 160 students of the Medical Faculty Christian University of Indonesia uses a validated questionnaire and SNOT-22 questionnaire. This study uses a descriptive method with a cross-sectional approach. The results of CRS prevalence in this study are 71 students $(44,4 \%)$, with a gender distribution are 52 students $(53,2 \%)$. The correlation of allergic history suspect with CRS is proven by a statistic test using chi-square with results $\mathrm{P}=0,003(\mathrm{P}>0,05)$ with a majority of the distribution is allergic rhinitis are 60 students $(90,1 \%)$. All respondents answered that CRS impacts their quality of life with most of the symptoms: nasal blockage/ obstruction and 36 students $(57,7 \%)$.

Keywords: Chronic Rhinosinusitis, Nasal Mucosa Inflammation, Allergic History, Allergic Rhinitis, Gender, Quality of Life.

\section{INTRODUCTION}

Chronic rhinosinusitis (CRS) is a health problem with a high incidence and prevalence in adults and children and significantly impacts the quality of life. CRS is inflammation of the nose and paranasal sinuses characterized by two symptoms, including nasal obstruction or mucopurulent nasal secretions/nasal discharge (anterior/posterior nasal drip), and maybe accompanied by facial pain and reduced ability to smell (hyposmia or anosmia) for 12 weeks ${ }^{1}$. CRS may also be accompanied by nasendoscopy results in nasal polyps and mucopurulent discharge originating from the middle meatus and obstructive oedema in the middle meatus. CRS can also be accompanied by computed tomography (CT) scan results in mucosal changes in the stomatal complex and paranasal sinuses $1 ; 2 ; 3$.

Research on the prevalence of CRS has been widely carried out throughout the world. According to the 2012 European Position Paper on Rhinosinusitis and Nasal Polyps (EPOS), it is estimated that CRS affects $5-15 \%$ of the adult population in Europe and the United States, with a physician-diagnosed prevalence of $2-4 \%{ }^{1}$. In Indonesia, the prevalence study at the ENT-KL polyclinic RSUD dr. Zainoel Abidin in 2012 obtained as many as 33 young and adult patients experiencing chronic rhinosinusitis, with a ratio of 14 men $(42.4 \%)$ and 19 women (57.6\%) ${ }^{4}$. In a study at the
Polyclinic of Dr M.Djamil Hospital in 2012, 63 cases of chronic rhinosinusitis were dominated by women $(60.32 \%)$ 5. Whereas in China, the prevalence of CRS using the diagnostic criteria by EPOS was $2.2 \%$ by telephone interview and $8 \%$ by face-to-face interview, patients also stated that their quality of life was impaired due to CRS 6 . The Sinonasal Outcome Test-22 (SNOT-22) is a questionnaire currently in development to precisely assess patients' quality of life with chronic rhinosinusitis. The SNOT-22 questionnaire prepared by Dr Jay Pic Cirilo was introduced in 2003 as a modification of the SNOT-20 questionnaire, namely by adding two questions, namely the presence or absence of nasal obstruction and changes in smell or taste 2 .

This study is expected to overview the prevalence of chronic rhinosinusitis in 2015 UKI Medical Faculty students and the risk factors that may influence and influence chronic rhinosinusitis on students' quality of life, especially in learning activities. The problem that will be answered in this study is "what is the prevalence of chronic rhinosinusitis in 2015 UKI Medical Faculty students in 2018?" with the aim of "to determine the prevalence of chronic rhinosinusitis in 2015 UKI Medical Faculty students in 2018".

\section{LITERATURE REVIEW}

The human respiratory tract is divided into two parts, namely the upper and lower respiratory tract. The CODEN (USA): JDDTAO 
respiratory tract is divided into the olfactory zone and the respiratory zone as a place for air to enter and exit. The respiratory tract also has a function as a sound producer for communication ${ }^{7}$. The upper respiratory tract consists of the outer and inner nose (chonca nasalis), nasopharynx, oropharynx, and laryngopharynx $6 ; 7$. The outer nose consists of the nasion at the base of the nose formed by the nasal bone and the frontal process of the maxillary bone. Then on the dorsum nasal to the apex, nasalis formed by the cartilage of the nasal septum and a pair of lateral cartilages ala major and ala minor. The medial edge of the superior lateral cartilage fuses with the nasal septal cartilage $8 ; 9 ; 10$. The inside of the nose starts from the anterior nasal aperture (anterior choanae or nares) to the nasal vestibule, which is the part that contains hair follicles, to the posterior nasal aperture (posterior choana), which separates the inside of the nose from the nasopharynx. The right and left nasal cavities are bounded by the nasal septal cartilage formed from the ethmoid bone. Each nasal cavity has a medial, lateral, superior and inferior mucosal wall 8;10;11.

The inferior part of the nasal wall is formed by the palatine bone of the maxillary bone and the horizontal plate of the palatine bone, and part of the lateral wall is formed by the perpendicular plate of the palatine bone $8 ; 10$. The inferior part of the nasal cavity and the oral cavity are separated by the hard palate formed by the maxillary bone and palatine bones ${ }^{8}$. The lateral wall can be divided into three parts, namely the anterior part, which is formed by the frontal process of the maxillary bone and the lamina cribrosa of the ethmoid bone (forming the superior and middle chonca), the inferior chonca and the posterior part formed by the perpendicular plate of the palatine bone and the medial pterygoid plate $8 ; 10$. The lacrimal bone also forms part of the lateral wall and forms the anterior border of the maxillary sinus ${ }^{8}$. The lateral wall forms the superior, middle and inferior nasal chonca between them, narrow slits, including the superior nasal meatus, middle nasal meatus, and inferior nasal meatus 12 . These narrow openings serve as the openings of the paranasal sinuses and the nasolacrimal duct in the nasal cavity ${ }^{7}$.

The superior meatus or ethmoid fissure is a narrow gap between the septum and the lateral mass of the ethmoid bone above the middle chonca. There is a spheno-ethmoid recess as the opening for the sphenoid sinus in the anteroposterior portion of the superior meatus. At the bottom of the superior nasal chonca are the sphenoid sinus and posterior ethmoid cells, opening into the nasal cavity 8 ; 13. In the middle meatus, the gap is wider than the superior meatus. This section is one of the gaps that contains the maxillary sinus, frontal sinus, and anterior ethmoid cellulae $8 ; 14$. In the inferior meatus, this gap is the largest compared to the third meatus; this section has the nasolacrimal duct that communicates with the lacrimal gland, this section is about $3.0-3.5 \mathrm{~cm}$ posterior to the anterior nasal aperture 8 ; 10.

Chronic rhinosinusitis (CRS) is inflammation of the nasal mucosa and paranasal sinuses characterized by two symptoms, including nasal obstruction or nasal secretions (anterior, posterior nasal drip), and maybe accompanied by facial pain and reduced ability to smell (hyposmia or anosmia) for 12 weeks 1 . CRS may also be accompanied by nasendoscopy results in nasal polyps and mucopurulent discharge originating from the middle meatus and obstructive oedema in the middle meatus. It can also be accompanied by the results of a computed tomography (CT) scan in the form of mucosal changes in the osteomeatal complex and paranasal sinuses $2 ; 15$.
Research on the prevalence of CRS has been widely carried out throughout the world. Rhinosinusitis and Nasal Polyps (EPOS), it is estimated that CRS affects $5-15 \%$ of the adult population in Europe and the United States, with a physician-diagnosed prevalence of $2-4 \%{ }^{16}$. In Indonesia, the prevalence study at the ENT-KL polyclinic RSUD dr. Zainoel Abidin in 2012 obtained as many as 33 young and adult patients experiencing chronic rhinosinusitis, with a ratio of 14 men (42.4\%) and 19 women (57.6\%) ${ }^{4}$. In research at the Polyclinic of Dr M. Djamil in 2012 found that 63 cases of chronic rhinosinusitis were dominated by women $(60.32 \%)$ 5. Whereas in China, the prevalence of CRS using the diagnostic criteria by EPOS was $2.2 \%$ by telephone interview and $8 \%$ by face-to-face interview, patients also stated that their quality of life was impaired due to CRS 6 .

The aetiology and pathophysiology of chronic rhinosinusitis are multifactorial and not fully understood; Chronic rhinosinusitis is a syndrome that occurs due to a combination of multiple etiologies. There are several opinions in categorizing the aetiology of chronic rhinosinusitis. Based on EPOS 2012, predisposing factors associated with the incidence of chronic rhinosinusitis without nasal polyps include ciliary impairment, allergies, asthma, increased sensitivity to aspirin, immunocompromised, genetic, pregnancy and endocrine factors, local factors of the patient (host), microorganisms that produce biofilm, environmental factors, iatrogenic factors, Helicobacter pylori, laryngopharyngeal reflux and osteitis 1 .

Rhinosinusitis is influenced by host factors, namely genetic and anatomical structure, agent and environmental factors. Pollutants such as cigarette smoke, dust, chemicals, allergic factors and infections can induce inflammation of the sinus mucosa. Inflammation of the sinus mucosa in allergic rhinitis in the paranasal sinus ostium can interfere with or obstruct the ventilation of the paranasal os, resulting in mucosal retention and infection. It can interfere with the airflow in the nose, which can interfere with the quality of life. In several studies, it was found that CRS patients had allergic predisposing factors because $54 \%$ of outpatients with CRS had positive results on skin prick test examinations.

Meanwhile, in CRS patients who underwent sinus surgery, the prevalence of positive results on skin prick test was $50 \%$ - $84 \%$, where the majority $(60 \%)$ experienced multiple sensitivity ${ }^{1}$. However, the role of allergy in CRS is still questionable because there is no increase in CRS incidence in sensitive flower patients during the spring season. Therefore, it can be concluded that the prevalence of CRS incidence increases in patients with allergic rhinitis as a predisposing factor, but the role of allergy in CRS itself is still unclear ${ }^{1}$

In the study, chronic rhinosinusitis patients of the female sex were more reported than male. It is due to differences in clinical symptoms that interfere with daily activities. The study found that adult patients with chronic rhinosinusitis with or without nasal polyps caused more clinical symptoms of facial pain/tenderness and dizziness in women, whereas clinical symptoms of nasal obstruction/congestion were more common in men. It is explained because chronic rhinosinusitis without nasal polyps is more common in women, whereas chronic rhinosinusitis with nasal polyps is more common in men ${ }^{1}$.

The pathophysiology of rhinosinusitis consists of 3 essential things that need to be assessed, namely: narrow paranasal sinus ostium, ciliary organ dysfunction and 
viscosity of sinus secretions ${ }^{17}$. A narrow paranasal sinus ostium can lead to obstruction and cause mechanical obstruction. Mechanical obstruction of the ostiomeatal complex (COM) triggers stasis of mucus secretion in the nasal cavity. It is associated with anatomic abnormalities and oedema of the nasal cavity mucosa caused by various etiologies 18, 20. Normal mucus secretion is assessed in terms of viscosity, volume, and composition; normal mucociliary transport to prevent mucus stasis and possible infection; as well as the anatomical structure of the osteomeatal complex to maintain drainage and airflow are sufficient to affect the health of everyone's paranasal sinuses ${ }^{19}$.

The osteomeatal complex (COM) is the drainage site for the anterior sinus group (frontal sinus, anterior ethmoid sinus and maxillary sinus). COM plays an essential role as mucus and debris transport and maintains sufficient oxygen tension to prevent the growth of surrounding bacteria 19 . Sinus ostium obstruction in COM is a predisposing factor that plays a significant role in the occurrence of chronic rhinosinusitis ${ }^{19}$. However, other predisposing factors also play a role in the occurrence of chronic rhinosinusitis. Interruption of one or more of the above factors will affect other factors and then progress to chronic rhinosinusitis with pathological changes in the sinus mucosa and the nasal mucosa, as illustrated in Figure 1 below ${ }^{19}$.

The bacterial infection that forms biofilms is also thought to be one of the causes of the persistence of chronic rhinosinusitis 18; 20. Biofilm is a complex matrix of polysaccharides synthesized by bacteria and acts as a protective microenvironment for bacterial colonies. Bacteria found in biofilms were 1000 times more resistant to antibiotics when compared to free bacteria of the same type. The presence of a biofilm helps explain the presence of a form of chronic rhinosinusitis that persists despite potent antimicrobial therapy. Studies have shown that bacterial biofilms are found in $75 \%$ of the mucosa of CRS patients with postoperative CRS nasal polyps $1 ; 18 ; 20$.

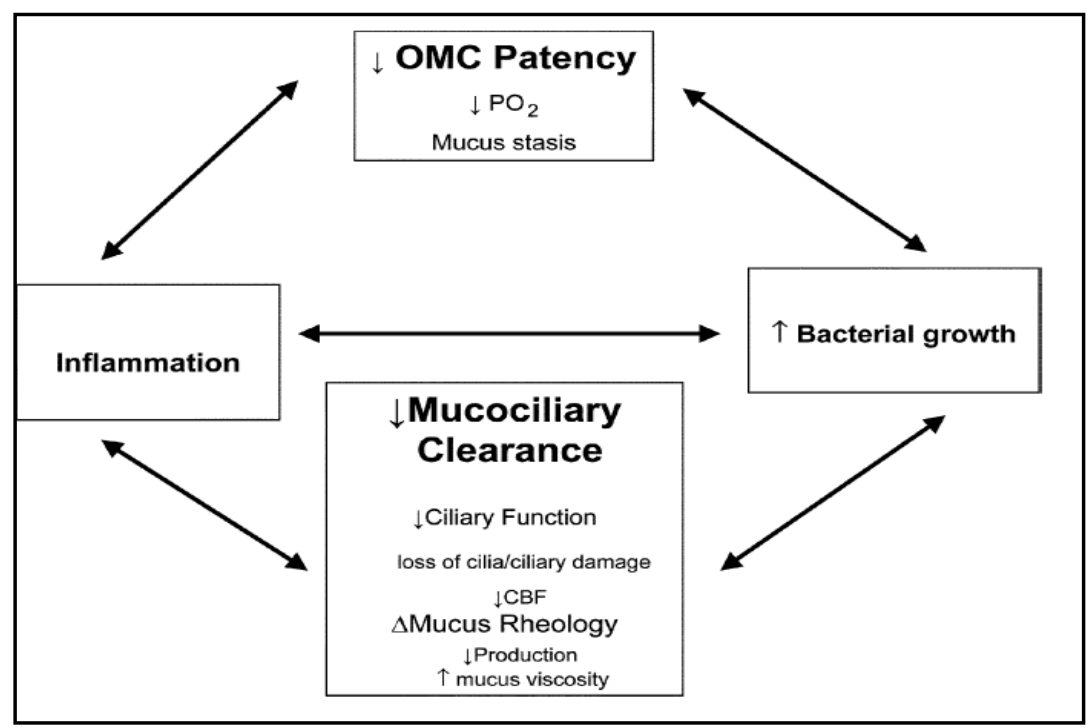

Figure 1: The pathological cycle of chronic rhinosinusitis, changes in one of the factors will result in a continuous process, with the result being chronic rhinosinusitis 19

In chronic rhinosinusitis, inflammation plays an essential role in pathogenesis ${ }^{20}$. Inflammatory processes are divided into 2, namely: infectious inflammatory groups and non-infectious inflammatory groups 21 . Infectious inflammation is common in acute rhinosinusitis, whereas non-infectious inflammation is common in chronic rhinosinusitis 20 . Irritation of the respiratory mucosa in the nasal cavity is an important initial phase in the incidence of chronic rhinosinusitis. The respiratory mucosa undergoes potential changes after exposure to bacteria, viruses, allergens, air pollution, superantigens and fungi $1 ; 20$. It increases ICAM-1 (intracellular adhesion molecule 1) as well as other cytokines. HLA-DR molecules (human leukocyte antigen DR) on the surface of epithelial cells also increase; these molecules play a role in specific immune responses that release various specific cytokines through TH1 and TH2. TH1 also releases Interferon-gamma (IFN- $\gamma$ ), which plays a role in increasing the production of ICAM-1 on the surface of respiratory epithelial cells. Epithelial cells also release GMCSF (granulocyte-macrophage-colony stimulating factor), IL8 and TNF- (necrosing tumour factor-alpha), which then affect macrophages, mastocytes, eosinophils and neutrophils 20. In chronic allergic rhinosinusitis, the released inflammatory mediators also have a role in the pathophysiology of sleep disorders, namely histamine, IL-1, IL-4, IL-6, IL-10. TNF-, PGD2, and bradykinin. IL-1, IL-6 and TNF- are cytokines that show a dominant role in sleep regulation 1; 20. It can cause sleep disturbances in patients with CRS, which can later affect the quality of life. 


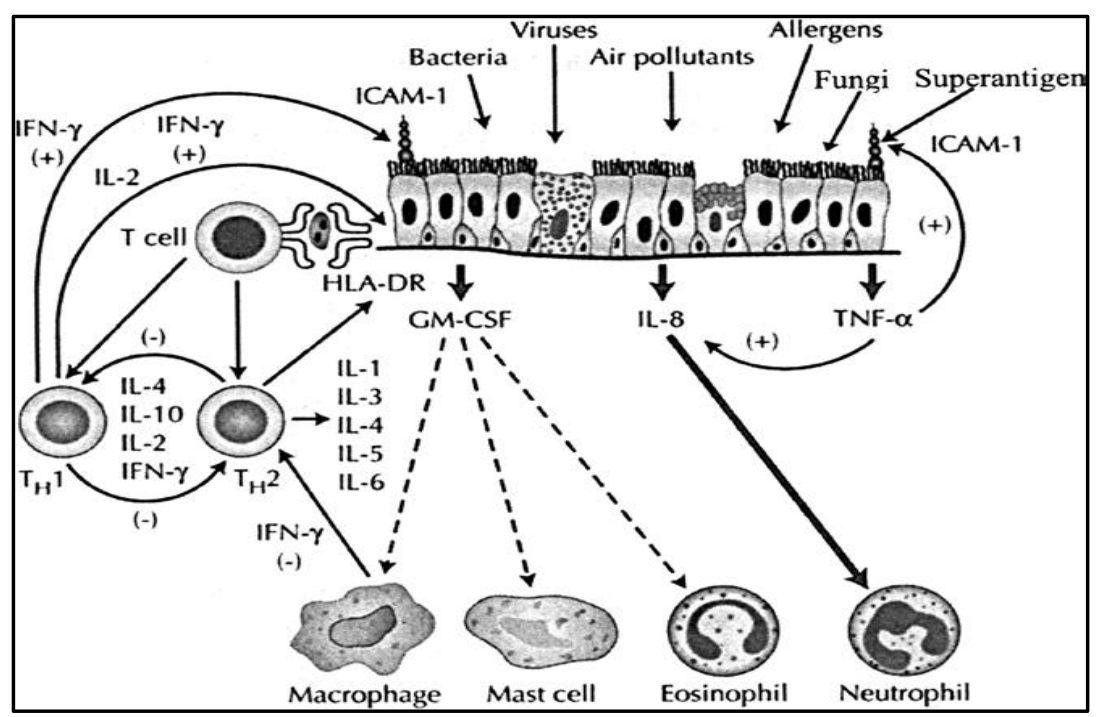

Figure 2: Schematic of changes in respiratory epithelial cells after exposure to foreign bodies, followed by various processes involving TH1 and TH2 lymphocytes, resulting in the release of cytokines and influencing phagocytic cells [20]

Histopathological features of chronic rhinosinusitis mucosa showed thickening of the mucous membrane base, goblet cell hyperplasia, atypical glands, subepithelial oedema, mononuclear cell infiltration papillary hyperplasia. Sometimes neutrophils and eosinophils are also found 20; 22; 23. The diagnosis of rhinosinusitis is usually made based on clinical signs and symptoms felt by the patient during history taking and physical examination. In addition, there are also supporting examinations that can be performed to validate the patient's clinical signs and symptoms, such as endoscopy and CT scan. This examination can also help determine the aetiology and predisposing factors of rhinosinusitis and determine therapy in patients 1 .

A careful and thorough history taking needs to be done, especially in assessing the signs and symptoms of rhinosinusitis in patients, because many patients can be diagnosed with chronic rhinosinusitis only based on the signs and symptoms experienced 1 . The results of the anamnesis in the form of complaints experienced, the location, quality and quantity of complaints, factors that relieve or aggravate, and a history of treatment for complaints significantly affect the diagnosis of rhinosinusitis. As for the cause of bacterial or viral infection, a background history of allergies or possible anatomic abnormalities of the nasal cavity can be considered from the results of a complete history $1 ; 20$. In addition, the severity of rhinosinusitis experienced by the patient can be assessed using methods/tests such as SNOT-22 (sinonasal outcome test), CSS (chronic rhinosinusitis survey) and RSOM-31 (rhinosinusitis outcome measure). However, this method/test is more often used for research purposes 20 .

A physical examination that can be done to establish the diagnosis of chronic rhinosinusitis is anterior rhinoscopy with sufficient headlight light and an airy nasal cavity (previously given a topical decongestant). On physical examination, nasal cavity abnormalities associated with chronic rhinosinusitis can be seen, such as chonca nasal oedema, hyperemic nasal mucosa, secretions (nasal drip), crusts, deviated septum, tumours or nasal polyps. In comparison, posterior rhinoscopy is performed only when necessary to view pathology at the back of the nasal cavity ${ }^{1}$ 20. Subjective assessment of the history and physical examination of acute or chronic rhinosinusitis can be established based on the following signs and symptoms $1 ; 20$; Nasal obstruction, congestion or nasal congestion; mucopurulent nasal discharge (anterior, posterior nasal drip); pain or pressure in the face, dizziness; impaired ability to smell (hyposmia or anosmia) $1 ; 20$.

Meanwhile, the diagnosis of chronic rhinosinusitis with or without nasal polyps in adults can be established from the history and physical examination results $1 ; 2 ; 3 ; 20$; Inflammation of the nasal mucosa and paranasal sinuses accompanied by two common symptoms of rhinosinusitis, one of which must be a nasal obstruction or congestion or nasal discharge (anterior or posterior nasal drip); may be accompanied by pain or pressure on the face and impaired ability to smell (hyposmia or anosmia); occurs for 12 weeks.

The following results may accompany the above signs and symptoms: Nasoendoscopy in nasal polyps and mucopurulent discharge from the middle meatus, and oedema/mucosal obstruction in the middle meatus. It can also be accompanied by CT-scan results in the form of mucosal changes in the osteomeatal complex and paranasal sinuses.

In addition to local signs and symptoms, there are also usual accompanying signs and symptoms such as dizziness, malaise, fever, sore throat, hoarseness and cough 1 . Investigations can be performed to validate the patient's clinical signs and symptoms, such as nasendoscopy, CT scan, transillumination and microbiological examination. This examination can also help determine the aetiology and predisposing factors of rhinosinusitis and determine therapy in the patient. ${ }^{1}$ Several things that can be assessed in the supporting examination are a) Nasoendoscopy; performed to assess the condition of the nasal cavity, presence/absence of secretions, osteomeatal complex, size of the nasal chonca, oedema around the tubal orifices, adenoid hypertrophy and appearance of the sinus mucosa; b) Transillumination; is a simple examination performed to assess the condition of the maxillary sinus. This examination is considered significant if there is a difference in transillumination between the right and left sinuses; c) Radiological examination; CT or MRI scans are commonly used. This examination is performed to assess the pathological process and sinus anatomy and evaluate advanced rhinosinusitis if medical treatment does not give good results. In addition, this examination is necessary for chronic rhinosinusitis who will undergo surgery. 
In addition, other investigations that can be performed to establish the aetiology of rhinosinusitis include nasal cytology, biopsy, aspiration puncture, and bacteriology are allergy tests such as skin prick tests, mucociliary function tests, ciliary vibration frequency, electron microscopy and nitric oxide. Assessment of nasal airflow, namely nasal inspiratory peak flow, rhinomanometry, acoustic rhinometry and rhinostereometry. Olfactory function tests, namely threshold testing, and laboratory tests, namely CRP (Creactive protein) examination.

Quality of life is a personal experience felt by a person that reflects health status and social and economic status in life 24 . One part that affects the quality of life is individual health. Health-related Quality of Life (HRQOL) is a person's quality of life influenced by health, disease, and disability, either directly or indirectly. A person's HRQOL is also influenced by age, culture, expectations and mental and physical abilities 24. According to EPOS 2012, chronic rhinosinusitis affects various aspects of quality of life 1 . Although the clinical symptoms of chronic rhinosinusitis are not life-threatening, they provide a significant reduction in the results of quality of life examinations in patients with chronic rhinosinocytosis 24 .

A study was conducted on rhinosinusitis patients with and without nasal polyps to assess the quality of life. In the assessment by nasendoscopy and CT-scan, chronic rhinosinusitis patients with nasal polyps had more severe clinical signs and symptoms when compared to chronic rhinosinusitis patients without nasal polyps. Nevertheless, assessing the quality of life using QoL assessment instruments and reducing the assessment associated with Nasal congestion showed that chronic rhinosinusitis patients with nasal polyps had a better quality of life when compared to chronic rhinosinusitis patients without nasal polyps ${ }^{24}$. It shows that in managing chronic rhinosinusitis, its effect on a person's quality of life can also be a measure of treatment success.

There are four aspects assessed on the quality of life of chronic rhinosinusitis patients: 1) Nasal symptoms; 2) Facial/ear symptoms; 3) Sleep disturbances; 4) Psychological changes. Nasal symptoms or olfactory organ dysfunction such as nasal congestion/nasal congestion, nasal discharge (anterior/posterior nasal drip), and reduced olfactory function (hyposmia/anosmia) are common clinical symptoms in patients chronic rhinosinusitis. This symptom is important to assess because it is considered a symptom that can later affect the other three aspects 25; 26. Patients with olfactory dysfunction are often reported to experience disturbances such as reduced appetite, difficulty preparing food, sleep disturbances and disturbances in concentration. Patients are also reported to be unable to detect odours such as food, gas, smoke, and chemicals. It can annoy patients with certain professions such as cooks, firefighters, plumbers, etc. 24; 25; 26. Disorders of olfactory function can also interfere with a person's life in terms of social, functional and emotional health. Therefore, chronic rhinosinusitis can interfere with a person's overall quality of life.

The Sinonasal Outcome Test-22 (SNOT-22) is a questionnaire currently in development to precisely assess the quality of life of patients with chronic rhinosinusitis. The SNOT-22 questionnaire was prepared by Dr Jay Pic Feature and introduced in 2003 to modify the SNOT-20 questionnaire, namely by adding two questions in the presence or absence of nasal obstruction and changes in smell or taste 2 . The addition of these two symptoms is because nasal obstruction is the symptom that is most often complained of to ENT-KL specialists, while the symptoms of olfactory disorders are the most frequent symptoms that do not improve after surgery Changes to the questionnaire make a valuable contribution to the assessment of the quality of life of patients with CRS. In SNOT-22, questions can be divided into four domains, namely: 1 . Nasal symptoms; 2 . Facial/ear symptoms; 3. Sleep disturbances; 4. Psychological changes aim to facilitate the assessment of the quality of life of patients with chronic rhinosinusitis. The National Comparative Audit of Surgery for Nasal Polyposis and Chronic Rhinosinusitis has validated SNOT-22 in English and has been used in research evaluating postoperative improvement.

SNOT-22 has also been translated and validated in several countries, namely: China, Czech Republic, Denmark, Lithuania, Iran, Greece, France, Portugal and Indonesia. In Indonesia, the results of the Spearman Rank SNOT-22 validity test by correlating the even question scores with the total score, and the odd question scores with the total score obtained respectively: $r s=0.961$ and $r s=0.978$ (valid: $r$ 0.7) and the results the correlation between even score and the odd score is $r s=0.900$. At the same time, the results of the SNOT-22 reliability test obtained Cronbach alpha $=0.936$ (Cronbach alpha 0.7: very reliable) ${ }^{2}$.

Following these results, it can be concluded that the translation of SNOT-22 can be used to consistently and precisely assess the quality of life of chronic rhinosinusitis patients. In addition, SNOT-22 can assist in increasing the effectiveness of the medical and operative treatment of CRS patients and their use in daily practice. With SNOT-22, it is possible to obtain standardized results and be compared with international studies ${ }^{2}$.

\section{RESEARCH METHOD}

The type of research used in this research is descriptive, using a cross-sectional approach. This research was conducted at the Faculty of Medicine, Christian University of Indonesia, Cawang, East Jakarta. This research was carried out from August 2018 to January 2019. The population that became the object of this research were 183 students of the Faculty of Medicine, Indonesian Christian University, batch 2015. The sample studied was the 2015 Indonesian Christian University Medical Faculty Students. Sampling in this study used the Non-Random Purposive Sampling technique where the questionnaire was given to the entire population, but the sample size was 2015 UKI Medical Faculty students who met the inclusion criteria. The instrument used in this study is a questionnaire with assessment criteria using a nominal scale of "yes" or "no" 1. The validity test was carried out using the Pearson productmoment correlation method with the SPSS statistical program. The research questionnaire is declared valid if $r_{\text {count }}$ $>r_{\text {table. }}$ The results of $r_{\text {count }}$ for each question item show that the $r_{\text {table }}$ value is above $(0.220)$, so the questionnaire is declared valid. In this study, the reliability test uses the Cronbach's Alpha formula and is declared reliable if the Cronbach's Alpha value is $>0.6$. Based on the reliability test results, Cronbach's Alpha was 0.920 , so the questionnaire was proven reliable. Before taking research data, the researcher asked for permission in writing to the Ethics Committee of the Faculty of Medicine, Christian University of Indonesia, by submitting an Ethical Clearance. After getting permission, the researcher collected data by giving questionnaires to the respondents by explaining the research objectives and asking for approval by signing the Informed Consent sheet. Research respondents have the right to accept or refuse to be included in this study. Every data obtained from respondents and related institutions is guaranteed to be confidential by the researcher. Data processing is carried 
out using the IBM SPSS Statistics 24.0 program, and the data is presented in the form of a table. The data were analyzed using frequency to determine the prevalence of respondents who have symptoms of chronic rhinosinusitis and to find out how many respondents who have symptoms of chronic rhinosinusitis also have a suspected history of allergies. After that, the data were also analyzed using chi-square to determine the relationship between chronic rhinosinusitis and a history of allergies and the relationship between chronic rhinosinusitis and quality of life.

\section{RESULT AND DISCUSSION}

This research was conducted at the Faculty of Medicine, the Christian University of Indonesia, for 2015 students. Questionnaires were given to the population, namely 2015 students who had agreed to become research respondents by signing the Inform Consent consent form. Of the 183 students from the 2015 batch, 160 students were willing to become respondents and complete all questionnaires, and 23 students were not willing to be respondents. Then 160 respondents were selected according to the inclusion and exclusion criteria determined and obtained 71 students from the 2015 class who became the research sample.

This study was conducted to determine the prevalence of chronic rhinosinusitis and determine if a history of allergies is associated with chronic rhinosinusitis and the effect of chronic rhinosinusitis on the quality of life of students of the Faculty of Medicine UKI batch 2015. This study used a questionnaire created by researchers to overview the presence or absence of symptoms. CRS experienced during the last 12 weeks and a description of the suspected history of allergies during the last year that happened to yourself or your family. After that, respondents also filled out the SNOT-22 questionnaire, which aims to determine what things are related to SSR that can interfere with the quality of life of respondents with CRS symptoms. The risk factor studied in this study was a history of allergies. In addition, the things that were assessed on the SNOT-22 questionnaire were nasal symptoms, facial/ear symptoms; sleep disturbances; and psychological changes.

Table 1: CRS prevalence

\begin{tabular}{lll}
\hline CRS & Number & $\%$ \\
\hline Yes & 71 & $44,4 \%$ \\
No & 89 & $55,6 \%$ \\
\hline Total & 160 & $100 \%$ \\
\hline
\end{tabular}

From the results of research conducted on 160 respondents, it can be seen in Table 1 that the frequency of respondents who experienced symptoms of chronic rhinosinusitis was 71 people (44.4\%) and as many as 89 people $(55.6 \%)$ who did not experience symptoms of chronic rhinosinusitis. After that, table 2 shows that 71 respondents who experienced CRS symptoms consisted of 52 women and 19 men.

Table 2: Gender distribution of respondents experiencing CRS symptoms

\begin{tabular}{lll}
\hline Gender & $\begin{array}{l}\text { Respondents experiencing } \\
\text { symptoms of CRS }\end{array}$ & $\mathbf{\%}$ \\
\hline Female & 52 & $73.2 \%$ \\
Male & 19 & $26.8 \%$ \\
\hline Total & $\mathbf{7 1}$ & $\mathbf{1 0 0 \%}$ \\
\hline
\end{tabular}

Table 3: Distribution of symptoms of respondents experiencing CRS symptoms

\begin{tabular}{lll}
\hline Experienced clinical symptoms & Number & $\%$ \\
\hline Nasal congestion & 65 & $91.5 \%$ \\
Nasal discharge (anterior/posterior nasal drip) & 59 & $83.1 \%$ \\
Pain/pressure on the face & 53 & $74.6 \%$ \\
Impaired ability to smell (hyposmia/anosmia) & 51 & $71.8 \%$ \\
Dizzy & 61 & $85.9 \%$ \\
Fever & 25 & $35.2 \%$ \\
Cough & 29 & $40.8 \%$ \\
\hline
\end{tabular}

In the study results, the distribution of symptoms experienced by 71 respondents who experienced CRS symptoms was also obtained. Symptoms of nasal congestion were 65 people $(91.5 \%)$, symptoms of nasal secretions (postnasal drip) were 59 people (83.1\%), symptoms of pain/pressure on the face were 53 people $(74.6 \%)$, symptoms of the ability to smell (hyposmia/anosmia) there are 51 people $(71.8 \%)$, dizziness symptoms are 61 people (85.9\%), fever symptoms are 25 people $(35.2 \%)$, and cough symptoms are 29 people $(40.8 \%)$.

Table 4: Frequency of the number of CRS who have and do not have a suspected history of allergies

\begin{tabular}{llcccc}
\hline & & \multicolumn{2}{c}{ Respondents experiencing symptoms of CRS } & Total & P-Value \\
\cline { 3 - 5 } & & Yes & No & & \\
\hline Allergy History & Yes & $64(40 \%)$ & $63(39.4 \%)$ & $127(79.4 \%)$ & \\
Suspected & No & $7(4.3 \%)$ & $26(16.25 \%)$ & $33(20.6 \%)$ & 0,003 \\
\hline Total & & $71(44.4 \%)$ & $89(55.6 \%)$ & $160(100 \%)$ & \\
\hline
\end{tabular}

In addition, in table 4, out of 160 respondents, 64 people $(40 \%)$, respondents who have CRS symptoms and have no suspected allergy history can be found as many as seven people (4.3\%). In addition, there were 63 respondents
(39.4\%) who did not experience CRS symptoms but with a suspected history of allergies, while 26 respondents (16.25\%). In this table, a chi-square statistical test was performed, the results showed that the suspected history of allergies was associated with the incidence of chronic rhinosinusitis with a value of $\mathrm{P}=0.003(\mathrm{P}<0.05)$. 
Table 5: Frequency distribution of suspected history of allergic rhinitis, asthma, eczema and hives in respondents who experience CRS symptoms

\begin{tabular}{llll}
\hline Allergy History Suspected & & CRS & Total \\
\hline Allergic Rhinitis & Yes & $60(90.1 \%)$ & $71(100 \%)$ \\
\cline { 2 - 4 } & No & $11(9.9 \%)$ & $71(100 \%)$ \\
\hline \multirow{2}{*}{ Asthma } & Yes & $20(28.2 \%)$ & $71(100 \%)$ \\
\cline { 2 - 4 } & No & $51(71.8 \%)$ & $71(100 \%)$ \\
\hline Eczema & Yes & $59(83.1 \%)$ & $70(28.2 \%)$ \\
\cline { 2 - 4 } & No & $51(71.8 \%)$ & \multirow{2}{*}{$710 \%$} \\
\hline \multirow{2}{*}{ hives } & Yes & No &
\end{tabular}

The frequency distribution in Table 5 shows that 71 respondents who had CRS symptoms who had a suspected history of allergic rhinitis were obtained as many as 60 people $(90.1 \%)$, suspected history of asthma as many as 20 people (28.2\%), suspected history of Eczema 12 people (16.9\%), and suspected history of hives 20 people (18.2\%).

The study results on 71 respondents who had CRS symptoms found that their quality of life was disturbed by filling out 22 questions assessed on the SNOT-22 questionnaire, but the quality of life was disturbed in patients with CRS symptoms. 'YES' on the questionnaire. In the distribution of impaired quality of life, four parts are assessed on the SNOT-22 questionnaire and carried out with a quality assessment, namely $0=$ not a problem and $5=$ severe problem. Therefore, the level of disturbing quality of life varies. After that, the SNOT-22 questionnaire also assesses what components (symptoms) are the most important perceived by the respondents that affect the quality of daily life.

Table 6: Distribution of symptoms as the most critical component that affects the quality of life of respondents with CRS symptoms

\begin{tabular}{|c|c|c|c|}
\hline \multirow[b]{2}{*}{ Symptoms felt } & \multicolumn{2}{|c|}{ Disruption of the patient's quality of life due to RSK } & \multirow[b]{2}{*}{ Total } \\
\hline & $\begin{array}{c}\text { Most Important } \\
\text { Component }\end{array}$ & Not the Most Important Component & \\
\hline Need to blow nose & $7(9,8 \%)$ & $64(90,2 \%)$ & $71(100 \%)$ \\
\hline Nasal congestion & $36(50,7 \%)$ & $35(49,3 \%)$ & $71(100 \%)$ \\
\hline Sneeze & $23(32,4 \%)$ & $48(67,6 \%)$ & $71(100 \%)$ \\
\hline Runny/runny nose & $27(38 \%)$ & $44(62 \%)$ & $71(100 \%)$ \\
\hline Cough Complaints & $17(24 \%)$ & $54(76 \%)$ & $71(100 \%)$ \\
\hline $\begin{array}{l}\text { Production of back nasal fluid (post- } \\
\text { nasal drip) }\end{array}$ & $30(42,3 \%)$ & $41(57,7 \%)$ & $71(100 \%)$ \\
\hline Thick nasal discharge & $21(29,6 \%)$ & $50(70,4 \%)$ & $71(100 \%)$ \\
\hline Ear fullness & $5(7 \%)$ & $66(93 \%)$ & $71(100 \%)$ \\
\hline Dizzy & $34(47,9 \%)$ & $37(52,1 \%)$ & $71(100 \%)$ \\
\hline Pain/pressure in the face & $9(12,7 \%)$ & $62(87,3 \%)$ & $71(100 \%)$ \\
\hline Decreased sense of smell/taste & $8(11,3 \%)$ & $63(88,7 \%)$ & $71(100 \%)$ \\
\hline Difficulty getting to sleep & $14(19,7 \%)$ & $57(80,3 \%)$ & $71(100 \%)$ \\
\hline Waking up at night & $9(12,7 \%)$ & $62(87,3 \%)$ & $71(100 \%)$ \\
\hline Lack of sleep at night & $14(19,7 \%)$ & $57(80,3 \%)$ & $71(100 \%)$ \\
\hline Woke up tired & $11(15,5 \%)$ & $60(84,5 \%)$ & $71(100 \%)$ \\
\hline Tired all day & $5(7,1 \%)$ & $66(92,9 \%)$ & $71(100 \%)$ \\
\hline Productivity drop & $12(16,9 \%)$ & $59(83,1 \%)$ & $71(100 \%)$ \\
\hline Decreased concentration & $18(25,4 \%)$ & $53(74,6 \%)$ & $71(100 \%)$ \\
\hline Frustrated & $4(5,6 \%)$ & $67(9,4 \%)$ & $71(100 \%)$ \\
\hline Sad & $2(2,8 \%)$ & $69(97,2 \%)$ & $71(100 \%)$ \\
\hline Shy & $2(2,8 \%)$ & $69(97,2 \%)$ & $71(100 \%)$ \\
\hline
\end{tabular}


Based on the research data in table 6, the distribution of the most critical components (symptoms) that affect the quality of life in 71 respondents who experienced CRS symptoms were complaints of having to blow their noses as many as 7 people $(9.8 \%)$, nasal congestion complaints as many as 36 people $(50.7 \%)$, complaints of sneezing as many as 23 people $(32.4 \%)$, complaints of runny/runny nose as many as 27 people (38\%), coughing complaints as many as 17 people (24\%), complaints of post-nasal drip production as many as 30 people (42.3\%), 21 people $(29.6 \%)$ complained of producing thick nasal fluid, 5 people (7\%), 34 people complained of dizziness $(47.9 \%), 7$ people complained of ear pain (9.9\%), pain complaints / pressure on the face as many as 9 people $(12.7 \%)$, complaints of reduced sense of smell/taste as many as 8 people $(11.3 \%)$, complaints of difficulty starting to sleep as many as 14 people (19.7\%), complaints of waking up at night as many as 9 people $(12.7 \%)$, complaints of lack of sleep at night 14 people $(19.7 \%)$, complaints of waking up tired as many as 11 people $(15.5 \%)$, complaints of fatigue throughout the day as many as 5 people (7.1\%), complaints of decreased productivity as many as 12 people $(16.9 \%)$, complaints of decreased concentration as many as 18 people (25.4\%), complaints of frustration as many as 4 people (5.6\%), complaints of sadness as many as 2 people $(2.8 \%)$, and complaints of shame as many as 2 people $(2.8 \%)$.

In a study of specific populations in America and Europe, it was found that the incidence of chronic rhinosinusitis (CRS) was more common in women with an age range of 18-64 years ${ }^{27}$. In the research at the ENT-KL Polyclinic, RSUP DR. M. Djamil and the ENT-KL Polyclinic, RSUD dr. Zainoel Abidin also found that the incidence of CRS was more common in women ${ }^{5}$. It is also evidenced in the results of research on 2015 UKI Faculty of Medicine students that in 160 respondents aged $20-22$ years who filled out the questionnaire, there were 71 people $(44 \%)$ who experienced symptoms of chronic rhinosinusitis with a gender distribution of 54 women $(73,2 \%)$ people while men 29 people $(28,6 \%)$. It is still unclear what causes women to experience chronic rhinosinusitis, but it is suspected that chronic rhinosinusitis is more common in women because women are more likely to experience ARI 5 .

In addition, the results of the study showed that the most felt clinical symptoms were nasal congestion as many as 65 people $(91.5 \%)$, followed by dizziness as many as 61 people $(85.9 \%)$ and nasal secretions (anterior/posterior nasal drip) as many as 59 people (83.1\%). In the study results at the ENT-KL Polyclinic, RSUP DR. M. Djamil, it was also found that the most felt symptom was nasal congestion $(88.89 \%)^{5}$. Nasal congestion or nasal obstruction is one of the most common symptoms experienced by patients with chronic rhinosinusitis 27. Nasal congestion or nasal obstruction can be caused by several things such as allergic rhinitis, nasal septal deviation, tumours, and others ${ }^{3}$. These symptoms are also commonly accompanied by nasal discharge/nasal discharge (anterior/posterior), reduced ability to smell (hyposmia/anosmia), facial pain/tenderness and dizziness, which have been reported to affect daily activities ${ }^{24}$.

A study found that the incidence of chronic rhinosinusitis was more common in people who had predisposing factors such as asthma and allergic rhinitis $1 ; 28$. In patients with chronic rhinosinusitis, the prevalence of allergic rhinitis ranges from $25-50 \% 20$. The results of this study obtained as many as 64 people $(40 \%)$ of respondents who had symptoms of CRS and had a suspected history of allergies. This study also showed that there was a relationship between the incidence of chronic rhinosinusitis and a suspected history of allergies with the results of the chi-square statistical test, the value of $P=0.003(P<0.05)$, which means the working hypothesis (H1) is accepted. In addition, the highest distribution of suspected allergic history was suspected allergic rhinitis, which was obtained by 60 people $(90.1 \%)$ of respondents, in the results of research at the ENT-KL Polyclinic, RSUD dr. Zainoel Abidin also found that 18 people $(57.6 \%)$ suffered from allergic rhinitis from 33 people with chronic rhinosinusitis 4 . Although many studies have shown a relationship between allergies and chronic rhinosinusitis, allergies can cause CRS is still not clearly understood 1; 20. In acute rhinosinusitis, according to Stammberber (1991), "nasal mucosal oedema in allergic rhinitis patients that occurs in the sinus ostium can reduce ventilation and even cause sinus ostium obstruction, resulting in mucus retention and infection" 1 . Meanwhile, it has not been explained if this condition's development and persistence can influence chronic rhinosinusitis 20 .

In the quality of life assessment, it was found that all respondents who experienced symptoms of chronic rhinosinusitis felt that their quality of life was disturbed. Therefore the statistical hypothesis could not be proven by a chi-square statistical test. In the assessment of the symptoms that most affect the quality of life, the most affecting symptoms were nasal congestion as many as 36 people $(50.7 \%)$ followed by dizziness as many as 35 people $(47.9 \%)$ and the production of back nasal fluid (post-nasal drip), as many as 30 people (42.3\%). According to research, these three symptoms are the most frequently reported symptoms that interfere with daily activities such as work, rest and sleep 24; 26. Disruption of this activity can cause more severe problems that affect the quality of life, such as sleep disturbances, psychological disorders (feeling disorders, depression and anxiety), fatigue and impaired sexual function. Therefore, it is essential to pay attention to the quality of life in assessing the management of chronic rhinosinusitis.

\section{CONCLUSION}

Based on the results of the study, it can be concluded as follows: a) The prevalence of chronic rhinosinusitis in the 2015 UKI Faculty of Medicine students in 2018 was 71 people (56\%) of 160 respondents with the most distribution of clinical symptoms being nasal congestion as many as 65 people (91.5\%), dizziness as many as 61 people $(85.9 \%)$ and nasal secretions (anterior/posterior nasal drip) as many as 59 people (83.1\%); b) Gender distribution of 71 respondents who had symptoms of chronic rhinosinusitis were 54 women $(73.2 \%)$ and 29 men $(28.6 \%) ; c)$ There is a relationship between suspected chronic rhinosinusitis and a suspected history of allergies as evidenced by the results of the chi-square statistical test, the value of $\mathrm{P}=0.003(\mathrm{P}<0.05)$. The frequency of respondents who have symptoms of chronic rhinosinusitis and have a suspected history of allergies is 64 people (40\%). The respondents who have symptoms of chronic rhinosinusitis and do not have a suspected history of allergies are 7 people $(4.3 \%)$; d) Distribution of suspected allergy history in 71 respondents who had symptoms of chronic rhinosinusitis were 60 people $(90.1 \%)$, asthma 20 people $(28.2 \%)$, eczema 12 people (16.9\%) and hives 20 people (18.2\%); and e) In the assessment of the quality of life, all 71 respondents who had symptoms of chronic rhinosinusitis stated that their quality of life was impaired, so the correlation could not be calculated with the chi-square statistical test. The distribution of clinical symptoms of chronic rhinosinusitis that most affected the quality of life was nasal congestion 36 
people $(50.7 \%)$, dizziness 35 people $(47.9 \%)$ and production of nasal fluid behind (post-nasal drip) 30 people $(42,3 \%)$.

\section{REFERENCES}

[1] Fokkens WJ, Lund VJ, Mullol J, Bachert C, Alobid I, Baroody F, Cohen N, Cervin A, Douglas R, Gevaert P, Georgalas C. EPOS 2012: European position paper on rhinosinusitis and nasal polyps 2012. A summary for otorhinolaryngologists. Rhinology. 2012 Mar 1; 50(1):1-2. https://doi.org/10.4193/Rhino50E2

[2] Juanda IJ, Madiadipoera T, Ratunanda SS, Lasminingrum L, Sudiro M, Dermawan A. Adaptasi Budaya. Alih Bahasa Indonesia dan Validasi Sino-Nasal Outcome Test (SNOT)-22. 2016; 978:38. https://doi.org/10.15395/mkb.v49n4.1145

[3] Ocampo CJ, Grammer LC. Chronic rhinosinusitis. The Journal of Allergy and Clinical Immunology: In Practice. 2013 May 1; 1(3):205-11. https://doi.org/10.1016/j.jaip.2012.12.001

[4] Husni T, Pradista A. Predisposing Factors for the Occurrence of Chronic Rhinosinusitis at the ENT-Client Clinic, Dr. Zainoel Abidin Banda Aceh. Jurnal Kedokteran Syiah Kuala. 2012; 12(3):132-7.

[5] Trihastuti H, Budiman BJ, Edison E. Profile of Chronic Rhinosinusitis Patients at the ENT-KL Polyclinic RSUP DR. M. Djamil Padang. Jurnal Kesehatan Andalas. 2015 Sep 1; 4(3). https://doi.org/10.25077/jka.v4i3.380

[6] Zhang Y, Gevaert E, Lou H, Wang X, Zhang L, Bachert C, Zhang N. Chronic rhinosinusitis in Asia. Journal of Allergy and Clinical Immunology. 2017 Nov 1;140(5):1230-9. https://doi.org/10.1016/j.jaci.2017.09.009

[7] Tortora GJ, Nielsen MT. Principles of human anatomy. John Wiley \& Sons; 2017 Aug 29.

[8] Paulsen F, Waschke J. Sobotta atlas anatomi manusia. Jakarta: Kedokteran EGC. Edisi. 2013;23.

[9] Wilson WR, Nadol JB, Randolph GW, Gulya AJ. The clinical handbook of ear, nose and throat disorders. New York. 2002.

[10] JJ B. Penyakit telinga, hidung, tenggorok, kepala dan leher. Edisi ke-13. Jilid satu. Jakarta: Binarupa Aksara. 1994:328-45.

[11] Drake RL, Vogl AW, Adam WMM. Gray's Anatomy for Students. 3rd ed. Vol. 3rd Editon. Elsevier Inc; 2014

[12] Kim YH, Park MG, Kim GC, Park BS, Kwak HH. Topography of the nasolacrimal duct on the lateral nasal wall in Koreans. Surgical and radiologic anatomy. 2012 Apr 1; 34(3):249-55. https://doi.org/10.1007/s00276-011-0858-y

[13] Ogle OE, Weinstock RJ, Friedman E. Surgical anatomy of the nasal cavity and paranasal sinuses. Oral and Maxillofacial Surgery Clinics. 2012 May 1; 24(2):155-66. https://doi.org/10.1016/j.coms.2012.01.011

[14] Wormald PJ. Three-dimensional building block approach to understanding the anatomy of the frontal recess and frontal sinus. Operative Techniques in Otolaryngology-Head and Neck Surgery. 2006 Mar 1; 17(1):2-5. Junqueira LC, Mescher AL. Junqueira's basic histology. McGraw-Hill Medical,; 2010. https://doi.org/10.1016/j.otot.2005.11.001
[15] Elsayed NM, Abdalaal LF. The Relation between Anatomical Variations of Osteomeatal Complex \& Nasal Structures and Chronic Sinusitis by Computed Tomography. Int J Med Imaging. 2015 Mar 8; 3(2):16-20. https://doi.org/10.11648/j.ijmi.20150302.12

[16] Passali D, Cingi C, Cambi J, Passali F, Muluk NB, Bellussi ML. A survey on chronic rhinosinusitis: opinions from experts of 50 countries. European Archives of Oto-Rhino-Laryngology. 2016 Aug; 273(8):2097-109. https://doi.org/10.1007/s00405-0153880-6

[17] Mustafa M, Patawari P, Iftikhar HM, Shimmi SC, Hussain SS, Sien MM. Acute and chronic rhinosinusitis, pathophysiology and treatment. Int J Pharm Sci Invent. 2015 Feb; 4(2):30-6.

[18] Brook I. Microbiology and antimicrobial treatment of orbital and intracranial complications of sinusitis in children and their management. International journal of pediatric otorhinolaryngology. 2009 Sep 1;73(9):1183-6. https://doi.org/10.1016/j.ijporl.2009.01.020

[19] Kilty SJ, Desrosiers MY. The role of bacterial biofilms and the pathophysiology of chronic rhinosinusitis. Current allergy and asthma reports. 2008 May 1; 8(3):227-33.

https://doi.org/10.1007/s11882-008-0038-2

[20] Flint PW. Cummings otolaryngology head and neck surgery, 5th edn. Mosby.

[21] Wilson M, Wilson PJ. Chronic Sinusitis. InClose Encounters of the Microbial Kind 2021 (pp. 225-231). Springer, Cham. https://doi.org/10.1007/978-3-030-56978-5_15

[22] Wu Y, Wang X, Huang D, Pei C, Li S, Wang Z. Gelomyrtol for acute or chronic sinusitis: A protocol for systematic review and meta-analysis. Medicine. 2020 Jun 5; 99(23). https://doi.org/10.1097/MD.0000000000020611

[23] Kaushal T, Gupta N, Singhal S, Chander J, Chavan BS. Quality of life in patients with fungal infection of nose and paranasal sinuses: A study from North India. Indian Journal of Social Psychiatry. 2017 Oct 1; 33(4):346. https://doi.org/10.4103/0971-9962.218607

[24] DeConde AS, Soler ZM. Chronic rhinosinusitis: epidemiology and burden of disease. American journal of rhinology \& allergy. 2016 Mar; 30(2):134-9. https://doi.org/10.2500/ajra.2016.30.4297

[25] Rudmik L, Smith TL. Quality of life in patients with chronic rhinosinusitis. Current allergy and asthma reports. 2011 Jun 1; 11(3):247-52. https://doi.org/10.1007/s11882-010-0175-2

[26] Ocampo CJ, Grammer LC. Chronic rhinosinusitis. The Journal of Allergy and Clinical Immunology: In Practice. 2013 May 1; 1(3):205-11. https://doi.org/10.1016/j.jaip.2012.12.001

[27] Halawi AM, Shintani Smith S, Chandra RK. Chronic rhinosinusitis: epidemiology and cost. InAllergy \& Asthma Proceedings 2013; 34(4). https://doi.org/10.2500/aap.2013.34.3675 